\title{
SECOND VIRIAL COEFFICIENTS FOR VAPOR-LIQUID EQUILIBRIUM CALCULATION*
}

KUNIO NAGAHAMA AND MITSUHO HIRATA

Dept. of Ind. Chem., Tokyo Metropolitan

University, Tokyo

\begin{abstract}
The second virial coefficient for pure compound is correlated as a power series of the reduced temperature. The three parameters of the equation were calculated by computer and in the calculations of second virial coefficients with all the substances investigated the errors were less than $5 \%$ over a substantially wide temperature range.

According to an assumed combination rule, the second virial cross coefficients are considered briefly.

With these second virial coefficients, an effect of the vapor-phase imperfection on vapor-liquid equilibrium has been investigated.
\end{abstract}

Up to moderate pressures, second virial coefficients of pure and mixed vapors are useful to estimate vaporphase imperfections in vapor-liquid equilibrium calculations. Numerous studies have been made in correlation of second virial cofficients from the principles of kinetic theory or from empirical relations. However, there were few attempts for polar substances or polarpolar mixtures. Presently the second virial coefficient for pure component is represented as a power series of the reduced temperature. The parameters of the equation were determined by a least square method and in our calculations with all the substances investigated the errors were less than $5 \%$.

A brief consideration is given of the second virial cross coefficient using a combination rule.

With the aid of these second virial coefficients, the liquid-phase activity coefficients taken into the vaporphase imperfections have been investigated.

\section{Introduction}

Real gases and vapors deviate from the simple law of the perfect gas. An accurate calculation or prediction of these deviations is important for calculation of vaporliquid equilibrium as well as the knowledge of the nonideality in liquid phase. Even the basic problem of determining the thermodynamic consistency of vaporliquid equilibrium data generally depends upon the availability of such information with respect to vapor phase.

Usually an equation of state is required to estimate the imperfection of gas or vapor phase. The most successful representation in the low-pressure region or in the range of most common separating operations is the virial equation truncated to the second virial coefficient. It has two features which make it particularly useful for engineering applications. First, one can derive the thermodynamic properties of gaseous substances more easily from the equation than from other equations

* Received on August 8, 1969 of state. Second, it is readily applicable to many polar substances. Though various equations of state have been used widely for nonpolar compounds, there has not been an excellent equation for polar compounds.

The virial equation suggested by Onnes ${ }^{17}$ in 1901 is represented in general by

$$
Z=\frac{P v}{R T}=1+\frac{B}{v}+\frac{C}{v^{2}}+\cdots
$$

where $Z$ is the compressibility factor, $v$ is the molal volume and $B, C$, etc., are virial coefficients with $B$ designated as the second virial coefficient, $C$ the third, etc.. For a given compound they are functions of temperature and composition only. Thus the virial equation terminated after the second virial coefficient:

$$
Z=\frac{P v}{R T}=1+\frac{B}{v}
$$

If $B$ represents the second virial coefficient for a gaseous $n$-component mixture, it is given exactly by

$$
B=\sum_{i}^{n} \sum_{j}^{n} y_{i} y_{j} B_{i j}
$$

where $B_{i j}=B_{j i}$, and $B_{i i}$ and $B_{j j}$ are the pure component second virial coefficients and $B_{i j}(i \neq j)$ is known as the interaction or cross coefficient at the temperature of the mixture. They are functions of temperature only.

For a binary mixture consisting of component 1 and 2, Eq. (3) becomes

$$
B=y_{1}^{2} B_{11}+2 y_{1} y_{2} B_{12}+y_{2}^{2} B_{22}
$$

For vapor-liquid equilibrium, it is ordinarily necessary to calculate the vapor-phase fugacity $f_{i}{ }^{*}$, of a component $i$ which may be expressed in terms of its mole fraction, $y_{i}$ the pressure, $P$ and the vapor-phase fugacity coefficient, $\varphi_{i}$ by

$$
f_{i}^{v}=\varphi_{i} y_{i} P
$$

Using Eq. (2), the fugacity coefficient of a component $i$ in a gas mixture is derived from some thermodynamic relations.

$$
\ln \varphi_{i}=\frac{2}{v} \sum_{j=1}^{n} y_{j} B_{i j}-\ln Z
$$

where $v$ may be found from Eqs. (2) and (3). 
Further approximations are possible for low pressure and similar truncation as well as Eq. (2) gives

$$
\ln \varphi_{i}=\frac{2 P}{R T} \sum_{j=1}^{n} y_{i} B_{i j}-B
$$

Comparing Eq. (6) with this, its advantage is that it is explicit in volume. This makes easier calculation of the fugacity coefficient at given values of $T$ and $P$. For a binary system made up of component 1 and 2 Eq. (7) becomes

$$
\begin{aligned}
& \ln \varphi_{1}=\frac{2 P}{R T}\left(y_{1} B_{11}+y_{2} B_{12}\right)-B \\
& \ln \varphi_{2}=\frac{2 P}{R T}\left(y_{2} B_{22}+y_{1} B_{21}\right)-B
\end{aligned}
$$

However, Eqs. (7), (8) and (9) do not usually represent data over so wide a range of pressure as does Eq. (6).

Numerous studies have been reported for second virial coefficients of nonpolar substances and a few of polar ones. Recently O'Connell and Prausnitz ${ }^{16)}$ suggested a new correlation of the second virial coefficient for polar gases. It was made through three factors, which were newly defined, i. e., the acentric factor of the polar substance's homomorph, the dipole moment and the association constant.

In 1958 Black $^{4}$ developed a semiempirical equation of state modified from van der Waals equation. It correctly furnishes the molal volumes for pure vapors and their mixtures as a function of temperature, pressure and composition in the pressure range up to about 90 to 95 $\%$ of the critical pressure. In the same paper he proposed a semiempirical correlation of second virial coefficients.

In this paper we have tried to develop the correlation of the second virial coefficients by recomputing its parameter from experimental information by a lease square method. When applying the new parameter to many substances investigated, one can find much better agreement with data than is afforded by the original parameter in Black's article ${ }^{4)}$.

\section{Pure Substances}

For pure gases, a good correlation of the second virial coefficient was given by Black ${ }^{4}$ based on modified van der Waals equation of state. It has the form

$$
B_{i i}=b_{i}-a_{i} \xi_{i}{ }^{0} / R T
$$

where $a$ and $b$ are the van der Waals constants calculated from the critical temperature $T_{c}$ and the critical pressure $P_{C}$ with the aids of

$$
\begin{aligned}
& b_{i}=R T_{c_{i}} / 8 P c_{i} \\
& a_{i}=27 b_{i} R T_{c_{i}} / 8
\end{aligned}
$$

The term of $a_{i} \xi_{i}{ }^{0}$ in Eq. (10) is assumed the molal cohesive energy of component $i$ at zero pressure. It is expressed by a function of the reduced temperature, namely

$$
\begin{aligned}
\xi_{i}{ }^{0}= & 0.396+1.181 / \operatorname{Tr}_{i}-0.864 / \operatorname{Tr}_{i}{ }^{2} \\
& +D / \operatorname{Tr}_{i}{ }^{3}+64 E / 27 \operatorname{Tr}_{i}{ }^{F}
\end{aligned}
$$

Black $^{4}$ divided the six terms in Eq. (13) into two parts. Accordingly, the first four terms are used for representing nonpolar substances with the aid of generalized constants $D(=0.384)$. In addition, an individual $D$ or the individual constants $E$ and $F$ are used for polar substances. When applying the generalized relation to many nonpolar substances, we often find that it may give somewhat poor results. Moreover, Black ${ }^{4}$ described the individual constants for only several polar compounds.

Here, we consider that Eq. (13) is to be used for all the compounds with individual constants $D, E$ and $F$, which make more accurate fit to numerous experimental data concerning second virial coefficients.

Consequently, even for nonpolar substances, three individual constants are necessary to determine the second virial coefficient in this correlation. In order that Eq. (13) be used satisfactorily, we determined the individual constants not only for 35 nonpolar substances but also for 40 polar substances.

Table 1 presents $D, E$ and $F$ for nonpolar substances and Table 2 for polar substances. In these Tables, critical constants $T_{c}\left({ }^{\circ} \mathrm{K}\right)$, and $P_{c}($ atm) are additionally indicated.

The constants of Eq. (13) were evaluated in the following manner. First we define the symbol $G$ by $G \equiv \xi_{i}{ }^{0}-0.396-1.118 / \operatorname{Tr}_{i}+0.864 / \operatorname{Tr}_{i}{ }^{2}$. Then Eq. (13) may be rearranged to the form:

$$
G=D / \operatorname{Tr}_{i}{ }^{3}+64 E / 27 \operatorname{Tr}_{i}{ }^{F}
$$

Eq. $\left(13^{\prime}\right)$ is not linear with respect to the parameters. The parameter $F$ is initially set at 4.75 and then the values of the parameters $D$ and $E$ are found by the method of least squares. In accordance with the results, the value of $F$ is incrementally varied until the best fit of the experimental data is indicated by a minimum in the least-square error with respect to the variable $F$. Furthermore the procedure is terminated when the total number of iterations may be beyond 50 trials. The flow diagram for this computation is shown in Fig. 1.

The best values of $D, E$ and $F$, which give the smallest sum of square errors, are presented in Tables

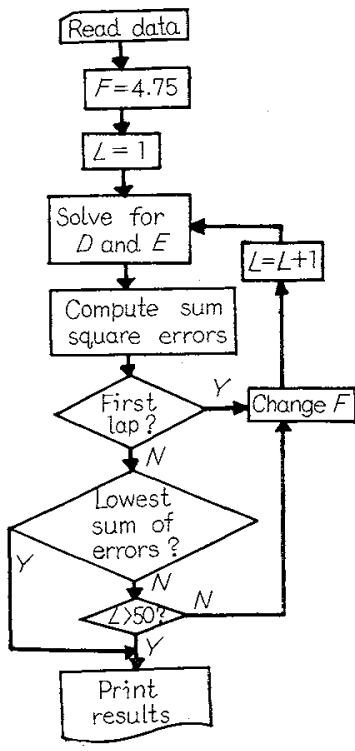

Fig. 1 Flow diagram for obtaining parameters 


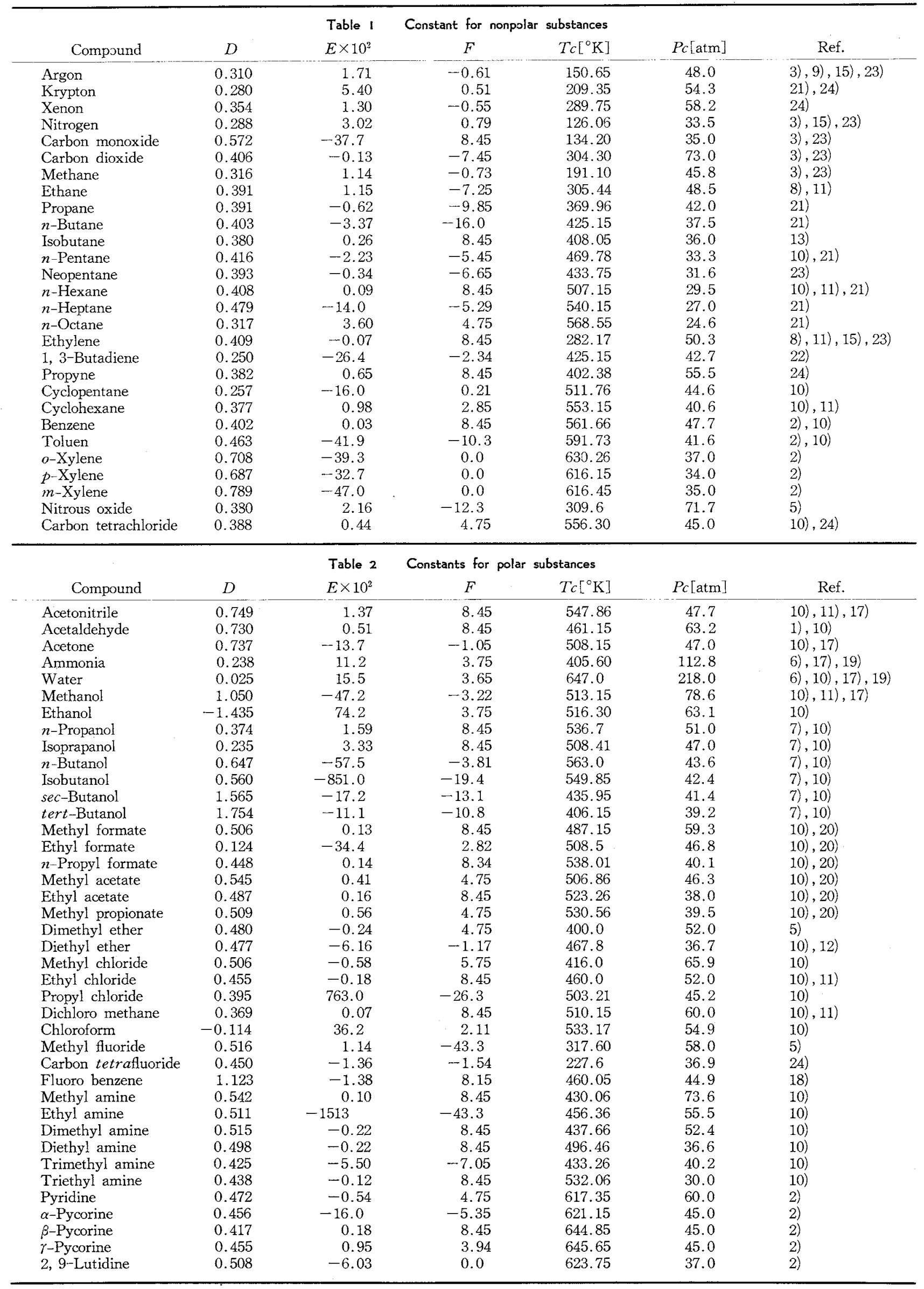


1 and 2. However, if the number of data points is two, $F$ is 0.0 and both $D$ and $E$ are determined by solving the simultaneous equations.

For pure gases, Table 3 gives the deviations calculated by both this and Black's correlations from experimental values. Evidently, the present correlation is far better than is Black's for every compound.

From Table 3 the largest m. a. m. d. (mean absolute magnitude deviation) is $31.78 \mathrm{ml} / \mathrm{mol}$ for $n$-hexane and its m. a. p. d. (mean absolute percentage deviation) is merely $2.67 \%$. Mostly for other nonpolar substances the m. a. m. d. are less than $5 \mathrm{ml} / \mathrm{mol}$. Table 3 shows also for polar gases that the m. a.m. d. is no more than $50 \mathrm{ml} / \mathrm{mol}$ except for acetonitrile, and m. a. p. d. is less than $5 \%$. While the experimental error is assumed to be $\pm 100 \mathrm{ml} / \mathrm{mol}$, these accuracies are sufficient for use. In the case of other polar substances which are not presented in Table 3, the m. a. p. d. are indicated below $5 \%$.

To clarify the above descriptions, a few examples are given in Figs. 2 and 3 which compare experimental results with calculated results for second virial coefficients. Fig. 3 includes also the calculated value from O'Connell and Prausnitz's correlation ${ }^{16)}$.

\section{Cross Coefficients for Gas Mixture}

For a good estimate of the cross coefficient $B_{j k}$, it is necessary to employ the correlating equation as mentioned before with suitable combination rules. Black ${ }^{4}$ described the second virial coefficient for a mixture as follows

$$
\begin{aligned}
B= & \sum_{i=1}^{n} b_{i} y_{i}-\left[\sum_{i=1}^{n}\left(a_{i} \xi_{i}{ }^{0 *}\right)^{0.5} y_{i}\right]^{2} / R T \\
& -\left[\sum_{i=1}^{n}\left(a_{i} \xi_{i}{ }^{0}\right)^{0.5} y_{i}\right]^{2} / R T
\end{aligned}
$$

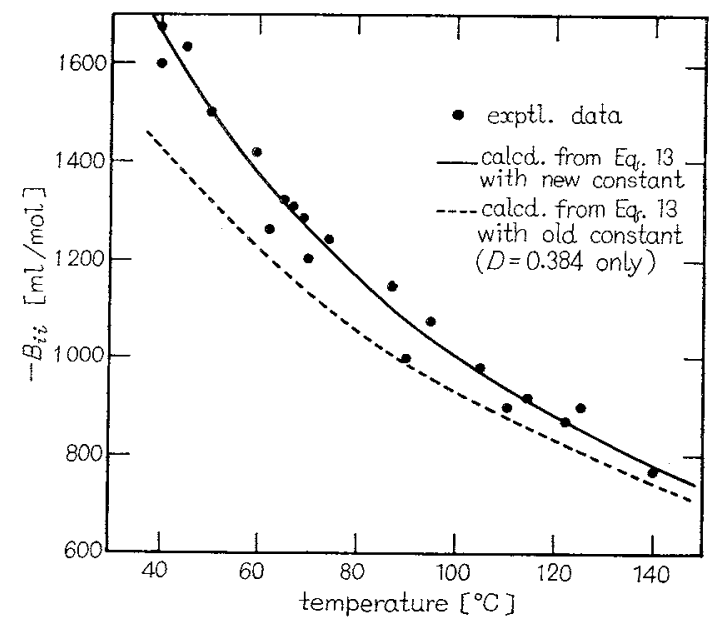

Fig. 2 Second virial coefficient for $n$-hexane

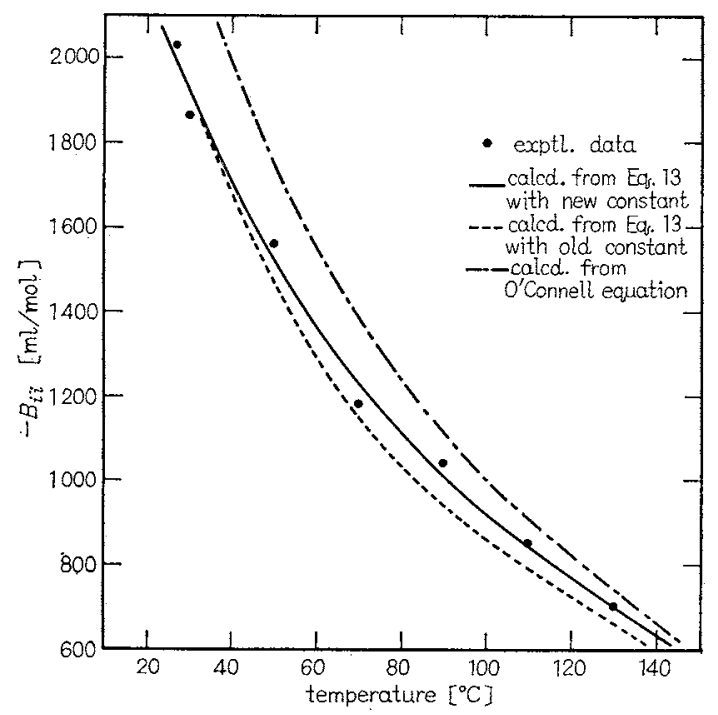

Fig. 3 Second virial coefficient for acetonce

\section{Table 3 Deviation of calculated from experimental second virial coefficients for pure substances}

Compound $\quad$ M.A., M.A. $\quad$ M.A. $\quad$ M.A. $\quad \begin{gathered}\text { No. of } \\ \text { data }\end{gathered}$

$[\mathrm{ml} / \mathrm{mol}][\%][\mathrm{m} l / \mathrm{mol}] \quad[\%]$ points

Nonpolar compound

$\begin{array}{lrrrrr}\text { Argon } & 2.31 & 3.31 & 12.15 & 33.35 & 48 \\ \text { Krypton } & 3.12 & 2.82 & 49.41 & 55.62 & 25 \\ \text { Xenon } & 0.60 & 2.60 & 2.91 & 11.56 & 12 \\ \text { Nitrogen } & 1.24 & 3.64 & 3.98 & 9.43 & 25 \\ \text { Carbon monoxide } & 0.38 & 3.06 & 0.98 & 8.88 & 8 \\ \text { Carbon dioxde } & 0.57 & 0.46 & 2.54 & 2.49 & 6 \\ \text { Methane } & 0.42 & 1.70 & 2.47 & 4.13 & 20 \\ \text { Ethane } & 0.06 & 0.02 & 9.25 & 4.86 & 3 \\ \text { Propane } & 2.15 & 0.78 & 4.65 & 1.92 & 12 \\ n \text {-Butane } & 2.43 & 0.45 & 15.11 & 2.86 & 12 \\ \text { Isobutane } & 18.93 & 2.88 & 39.69 & 5.75 & 11 \\ n \text {-Pentane } & 10.48 & 1.35 & 46.50 & 5.36 & 18 \\ \text { Neopentane } & 3.34 & 0.63 & 9.00 & 2.05 & 16 \\ n \text {-Hexane } & 31.78 & 2.67 & 118.4 & 9.12 & 21 \\ n \text {-Heptane } & 2.37 & 0.17 & 226.2 & 15.15 & 7 \\ n \text {-Octane } & 7.34 & 0.39 & 359.2 & 19.32 & 10 \\ \text { Ethylene } & 2.21 & 1.63 & 4.77 & 2.82 & 10 \\ \text { 1,3-Butadiene } & 1.59 & 0.61 & 315.6 & 12.98 & 5 \\ \text { Propyne } & 1.01 & 0.55 & 4.03 & 1.80 & 10\end{array}$

M. A. M. D. : Mean Absolute Magnitude Deviation M. A.P. D.: Mean Absolute Percentage Deviation

I... calculated from present work with the individual

\begin{tabular}{|c|c|c|c|c|c|}
\hline \multicolumn{6}{|c|}{ second virial coefficients for pure substances } \\
\hline Compound & $\begin{array}{l}\text { M.A. } \\
\text { M.D.' } \\
{[\mathrm{m} l / \mathrm{mol}]}\end{array}$ & $\begin{array}{l}\text { M.A. } \\
\text { P.D } \\
{[\%]}\end{array}$ & $\begin{array}{l}\text { M.A. } \\
\text { M.D." } \\
{[\mathrm{ml} / \mathrm{mol}]}\end{array}$ & $\begin{array}{l}\text { M.A. } \\
\text { P.D." } \\
{[\%]}\end{array}$ & $\begin{array}{c}\text { No. of } \\
\text { data } \\
\text { points }\end{array}$ \\
\hline Cyclopentane & 0.79 & 0.29 & $\ldots$ & & 5 \\
\hline Cyclohexane & 18.53 & 1.79 & 48.61 & 4.17 & 15 \\
\hline Benzene & 17.28 & 2.29 & 29.09 & 3.40 & 19 \\
\hline Toluene & 13.74 & 1.11 & 196.9 & 15.70 & 7 \\
\hline Nitrous oxide & 0.09 & 0.06 & 3.61 & 2.75 & 3 \\
\hline $\begin{array}{l}\text { Carbon } \\
\text { tetrachloride }\end{array}$ & 6.79 & 0.56 & 101.19 & 8.20 & 6 \\
\hline \multicolumn{6}{|l|}{ Polar compound } \\
\hline Acetonitrile & 88.48 & 2.85 & 202.37 & 5.49 & 11 \\
\hline Acetaldehyde & 23.19 & 2.37 & 35.21 & 3.97 & 8 \\
\hline Acetone & 32.98 & 2.36 & 51.96 & 4.39 & 7 \\
\hline Ammonia & 0.59 & 0.65 & 2.76 & 0.83 & 6 \\
\hline Water & 1.27 & 0.42 & 7.87 & 2.92 & 7 \\
\hline Methanol & 13.72 & 1.80 & 34.20 & 4.56 & 9 \\
\hline Ethanol & 49.80 & 3.47 & 249.31 & 12.27 & 6 \\
\hline Dimethyl ether & 2.38 & 0.50 & 4.19 & 0.81 & 3 \\
\hline Diethyl ether & 1.74 & 2.04 & 24.83 & 3.11 & 7 \\
\hline Methyl chloride & e 5.01 & 1.03 & 12.77 & 2.84 & 7 \\
\hline Chloroform & 13.98 & 1.61 & 56.60 & 7.03 & 8 \\
\hline Methyl fluoride & 0.58 & 0.25 & 2.22 & 1.15 & 3 \\
\hline
\end{tabular}
constants
"... calculated from Black's work with the generalized constant for nonpolar compounds and the individual constants for polar compounds which are presented in his article 


$$
\xi_{i}{ }^{*}=0.396+1.181 / \operatorname{Tr}_{i}-0.864 / \operatorname{Tr}_{i}{ }^{2}
$$$$
+0.384 / \operatorname{Tr}_{i}{ }^{3}
$$

and

$$
\bar{\xi}_{i}{ }^{0}=\xi_{i}{ }^{0}-\xi_{i}{ }^{0 *}
$$

From Eq. (14) we derive the cross coefficient $B_{j k}$ for a binary system consisting of components $j$ and $k$.

$$
\begin{aligned}
B_{j k}= & \frac{b_{j}+b_{k}}{2}-\left(a_{j} a_{k}\right)^{0.5}\left[\left(\xi_{j}{ }^{* *} \xi_{k}{ }^{0 *}\right)^{0.5}\right. \\
& \left.+\left(\bar{\xi}_{j}{ }^{0} \xi_{k}{ }^{0}\right)^{0.5}\right] / R T
\end{aligned}
$$

In Eq. (16), the term of $\xi_{i}{ }^{0}$ is given by Eq. (13). Namely $\xi_{i}{ }^{0 *}$ indicates the nonpolar part with $\bar{\xi}_{i}{ }^{0}$ designated as the polar part. If each of the gases is a nonpolar substance, the $\bar{\xi}_{i}{ }^{0}$ are each equal to zero. Eq. (17) gives a good estimate for a given mixture which is either nonpolar-nonpolar or nonpolar-polar system. However, we have not employed such a division as in Eqs. (14) and (17). The following correlation is used to furnish the $B_{j k}$ for the same mixture as previously mentioned.

$$
B_{j k}=\frac{b_{j}+b_{k}}{2}-\left(a_{j} a_{k}\right)^{0.5}\left(\xi_{j}{ }^{0} \xi_{k}{ }^{0}\right)^{0.5} / R T
$$

where $\xi_{j}{ }^{0}$ and $\xi_{k}{ }^{0}$ are given by Eq. (13).

For mixture of polar gases in which special chemical effects are present, individual binary coefficients are required. These coefficients are properties of the binarjes and are not readily predicted from the data for the pure components. To take these into account, binary terms with empirical coefficients are added to Eq. (17) or Eq. (18) to furnish

$$
B_{j k}=\mathrm{Eq} .(17)(\text { or }(18))-\frac{1}{2} E^{\prime} / T_{r_{j k}^{\prime} F^{\prime}}
$$

where

$$
\operatorname{Tr}_{j k}=T /\left(T c_{j} T_{c_{k}}\right)^{0.5}
$$

Binary coefficients are probably required in any mixture in which strong interassociation or "compound" formation takes place between unlike molecules, one or more of which is relatively nonassociated in the pure vapor state. In practice, few data are available for these systems to calculate the binary coefficients.

The applications of Eqs. (17) and (18) to mixtures containing nonpolar and polar gases are illustrated with three binary systems in Table 4. The $B_{j k}$ s for the systems acetonitrile-acetaldhyde are calculated through the binary constants.

The results from Table 4 show that Eq. (17) appears to be accurate in fitting data for nonpolar-nonpolar and nonpolar-polar mixtures. If the $B_{j k}$ has a great difference from both $B_{j j}$ and $B_{k i k}$ such as for the acetonitrileacetaldehyde system, the binary constants are usually required.

\section{Vapor Phase Imperfection in Vapor-Liquid Equilibria}

In vapor-liquid equilibrium, for a first approximation of the influence of pressure on liquid phase, the molal and partial molal volume in liquid phase, designated as $V_{i}{ }^{L}$ and $\bar{V}_{i}{ }^{L}$, are assumed to be equal and independent of pressure. Further, if the standard reference pressure is the vapor pressure $P_{i}{ }^{0}$ at a given temperature, the vapor-liquid equilibrium is given by

$$
\begin{aligned}
\ln \gamma_{i}= & \ln \left(y_{i} P / x_{i} P_{i}{ }^{0}\right)+\ln \left(\varphi_{i} / \varphi_{i}{ }^{0}\right) \\
& -V_{i}{ }^{L}\left(P-P_{i}{ }^{0}\right) / R T
\end{aligned}
$$

where $\gamma_{i}$ is the liquid-phase activity coefficient. With the aid of Eq. (7), the required relation for vapor-liquid equilibrium calculations is given by

$$
\begin{aligned}
\ln \gamma_{i}= & \ln \left(y_{i} P / x_{i} P_{i}{ }^{0}\right)+\frac{\left(B_{i i}-V_{i}{ }^{L}\right)\left(P-P_{i}{ }^{0}\right)}{R T} \\
& +\frac{P}{R T}\left(2 \sum_{j=1}^{n} B_{i j} y_{j}-B_{i i}-B\right)
\end{aligned}
$$

For binary systems the third term is simplified as follows

$$
\begin{aligned}
\ln \gamma_{1}= & \ln \left(y_{1} P / x_{1} P_{1}^{0}\right)+\frac{\left(B_{11}-V_{1}^{L}\right)\left(P-P_{1}^{0}\right)}{R T} \\
& +\frac{P}{R T^{-\delta_{12} y_{2}{ }^{2}}} \\
\ln \gamma_{2}= & \ln \left(y_{2} P / x_{2} P_{2}{ }^{0}\right)+\frac{\left(B_{22}-V_{2}^{L}\right)}{R T} \frac{\left(P-P_{2}{ }^{0}\right)}{R T} \\
& +\frac{P}{R T} \delta_{12} y_{1}^{2}
\end{aligned}
$$

where $\delta_{12}=2 B_{12}-B_{11}-B_{22}$

If the total pressure $P$ is below several atmospheres and the difference of $\left(P-P_{i}{ }^{0}\right)$ is by only a few atmospheres, Eqs. (22), (23) and (24) sufficiently useful. In the pressure range near or below one atmosphere, one adopts sometimes the simplified relation given as

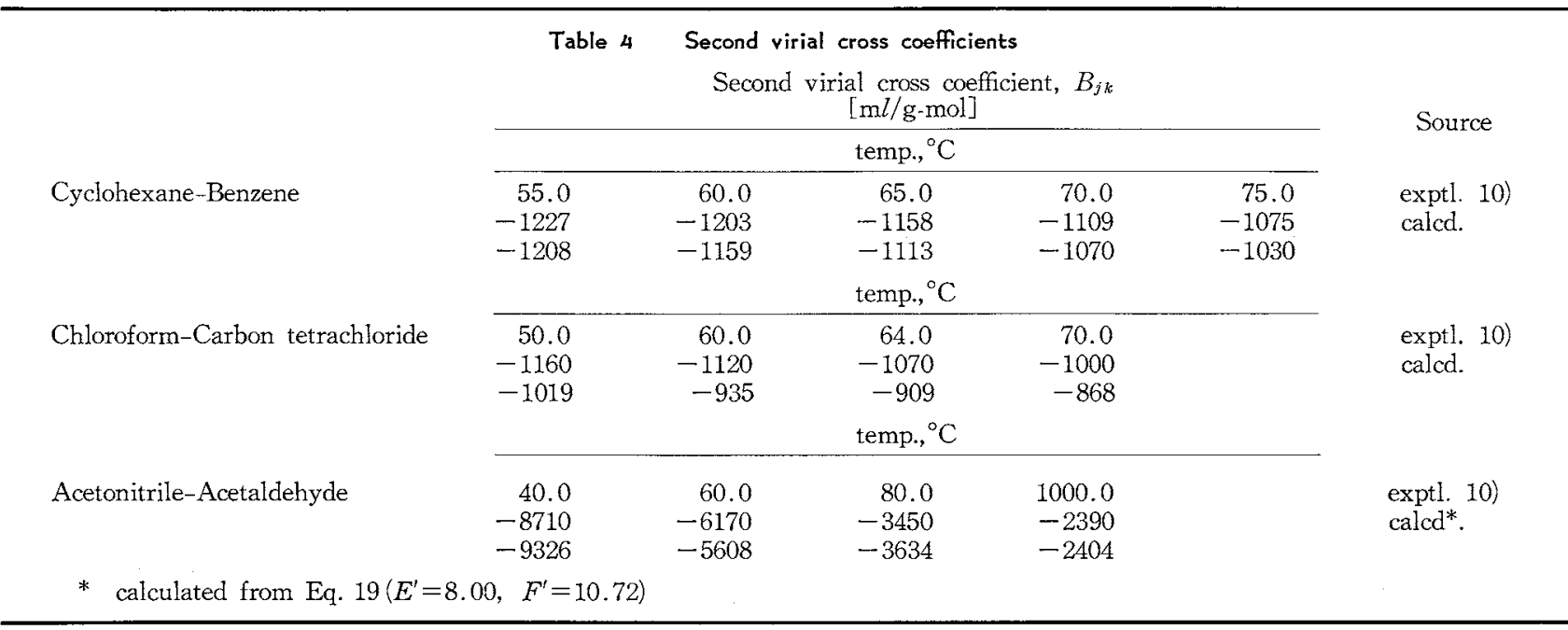




$$
\ln \gamma_{i}=\ln \left(y_{i} P / x_{i} P_{i}^{0}\right)
$$

Here $\gamma_{i}$ calculated by Eq. (22) is denoted by $\gamma_{i}^{\prime}$ and $\gamma_{i}$ of Eq. (25) by $\gamma_{i}^{\prime \prime}$. Fig. 4 shows these activity coefficients as a function of the liquid composition for the system isoprene-acetonitrile at $3.1 \mathrm{~atm}^{14)}$. It has a boiling range of about $50^{\circ} \mathrm{C}$ and the azeotropic point. In the case of this system, one can find that clearly the $\gamma_{i}^{\prime}$ 's are more consistent than the $\gamma_{i}^{\prime \prime}$. As a further illustration we consider the mixture acetonitrile-water at $3.0 \mathrm{~atm}^{14)}$. We have also plotted in Fig. 5 both the $\gamma_{i}$ s and the $\gamma_{i}^{\prime \prime}$ s, which shows that equally reasonable values are obtained by $\gamma_{i}^{\prime \prime}$ in Eq. (25) as by $\gamma_{i}^{\prime}$ in Eq. (22). The boiling temperature range of the acetonitrilewater system is only about $20^{\circ} \mathrm{C}$, and this causes the consistency of two different treatments.

However, if the boiling range is reasonably wide or the total pressure and the vapor pressure of pure components differ by a few atmospheres, one should make use of Eq. (22) for calculating the liquid-phase activity coefficients.

\section{Summary}

To calculate the second virial coefficient, a correlation based on Black's equation was investigated empirically and the individual constants $D, E$ and $F$ were determined for various pure fluids by use of computer. Calculated values were reasonably coincident with experimental data.

Brief consideration was given to the second virial cross coefficients.

With the aid of these considerations, taking into account the vapor-phase imperfections the liquid-phase activity coefficients were calculated.

\section{Nomenclature}

\begin{tabular}{|c|c|}
\hline$a$ & $=$ van der Waals constant \\
\hline$b$ & $=$ van der Waals constant \\
\hline$B$ & $=$ second virial coefficient \\
\hline$C$ & $=$ third virial coefficient \\
\hline$D, I$ & $=$ constants in Eq. (13) \\
\hline$E^{i}$, & $=$ binary constants in Eq. (19) \\
\hline$f$ & $=$ fugacity \\
\hline$P$ & $=$ total pressure \\
\hline$P^{0}$ & $=$ vapor pressure \\
\hline$P C$ & $=$ critical pressure \\
\hline$R$ & $=$ universal gas constant \\
\hline$T$ & $=$ absolute temperature \\
\hline$T c$ & $=$ critical temperature \\
\hline $\operatorname{Tr}$ & $=$ reduced temperature $=T / T c$ \\
\hline$v$ & $=$ molal volume, vapor \\
\hline$V^{L}$ & $=$ molal volume, liquid $\quad[\mathrm{m} l / \mathrm{g}-\mathrm{mo}$ \\
\hline$V_{i}^{L}$ & 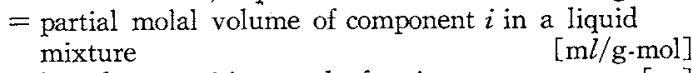 \\
\hline$x$ & $=$ liquid composition, mole fraction \\
\hline$y$ & $=$ vapor composition, mole fraction \\
\hline$Z$ & mpressibility factor \\
\hline 7 & $=$ activity coefficient in liquid phase \\
\hline$\xi^{0}$ & $=$ an attraction coefficient at zero pressure \\
\hline$\xi^{0 *}$ & $=$ nonpolar part of attraction coefficient \\
\hline $\bar{\xi}^{0}$ & $=$ polar part of attraction coefficient \\
\hline$\varphi$ & $=$ fugacity coefficient \\
\hline$\varphi^{0}$ & $=$ fugacity coefficient at saturated pressure \\
\hline
\end{tabular}

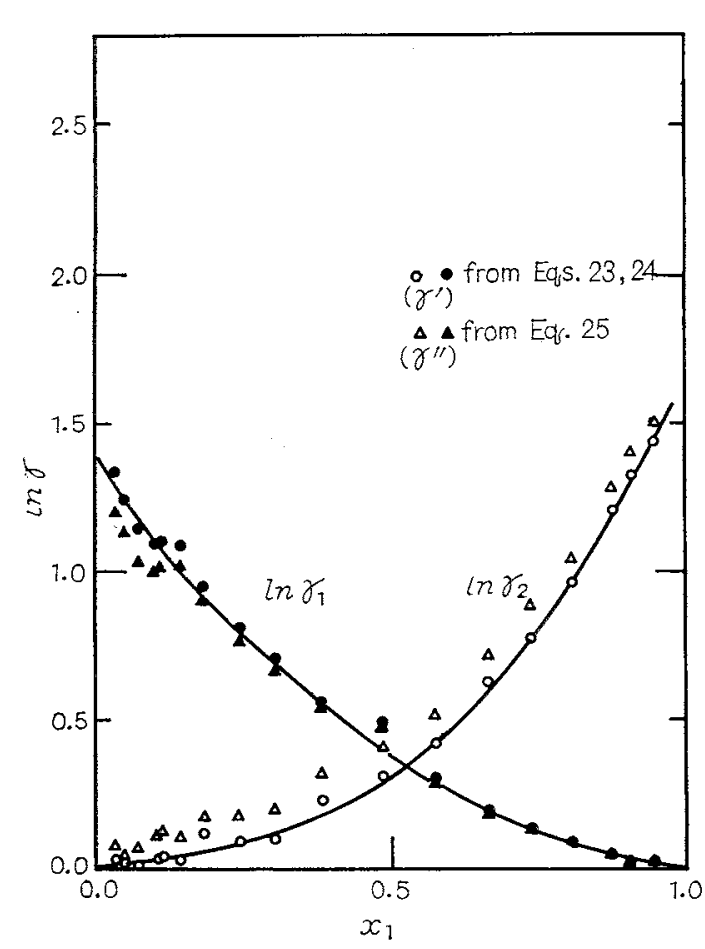

Fig. 4 Comparison of $\ln \gamma$ for the system isoprene (1)-acetonitrile (2) at 3.1 atm.

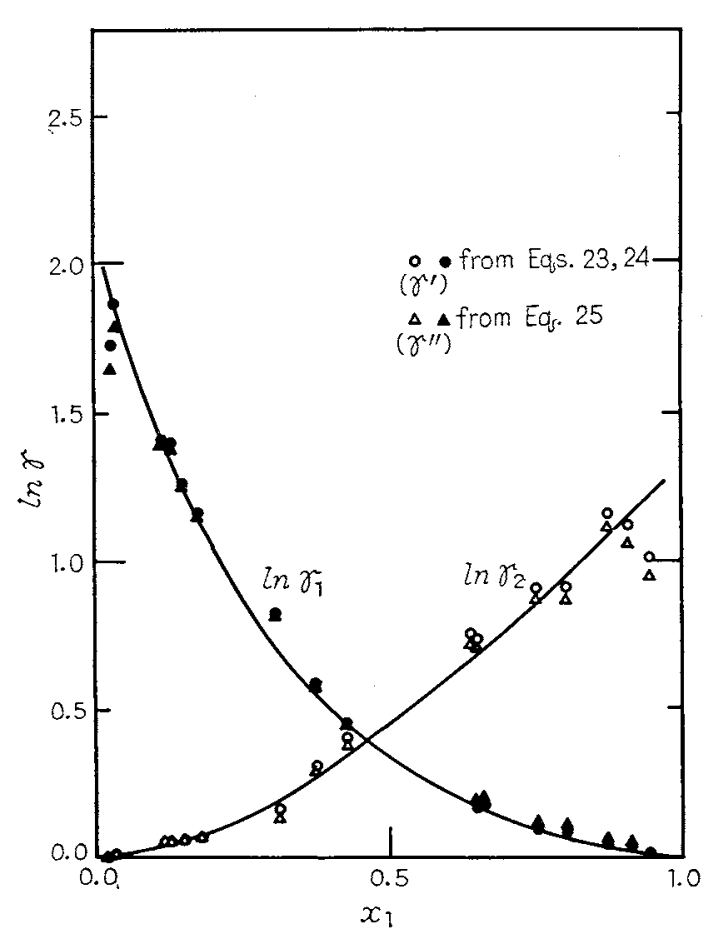

Fig .5 Comparision of In $\gamma$ for the system acetonitrile (1)-water (2) at $3.0 \mathrm{~atm}$.

\section{Literature cited}

1) Alexander, E. A. and J. C. Lambert: Trans. Faraday Soc., 37, 421 (1941)

2) Andon, R. J. L., J. D. Cox, E. F. G. Herington and J. F. Martin: Trans. Faraday Soc., 53, 1074 (1957)

3) Bird, R. B. and E. L. Spotz: University of Wisconsin, NOrd 9938, Task Wisl-C, CM-599 (May 10, 1950)

4) Black, C.: Ind. Eng. Chem., 50, 391 (1958) 
5) Cawood, W. and H. S. Patterson: J. Chem. Soc., 1933, p. 619

6) Collins, S. C. and F. G. Keyes: Proc. Am. Acad. Arts Sci., $72,283(1938)$

7) Cox, J. D.: Trans. Faraday Soc., 57, 1674 (1961)

8) Eucken, A. and A.Z. Parts: Z. physik. Chem., B20, 184 (1933)

9) Itterbeek, A. van and van, O. Paemel: Physica, 5, 145 (1938)

10) Kogan, V. B., V. M. Fridman and V. V. Kafarov: Equilibrium between liquid and vapor, Nauka, Moscow (1966)

11) Lambert, J. D., G. A. H. Roberts. J. S. Rowlinson and V. J. Wilkinson: Proc. Roy. Soc., A 196, 113 (1949)

12) Landort, $H$. and R. Börnstein: Physikalisch-Chemische Tabellen, 5th ed., Vol. 2, Suppl. 3, Sect. 78 AW, J. Springer, Berlin, 1935

13) MacCallum, R. N. and J. J. McKetta: Hydrocarbon Processing, 40 (5), 191 (1963)

14) Nagahama, K.: M. thesis, Dept. of Technology, Tokyo
Metropolitan University, Tokyo, (1968)

15) Natl. Bur. Standards (U. S.): Tables of Thermal Properties of Gases, Circ. 564 (Nov. 1, 1955)

16) O'Connell, J. P. and J. M. Prausnitz: Ind. Eng. Chem. Process Design and Development, 6, 245 (1967)

17) Rowlinson, J.S.: Trans. Faraday Soc., 45, 974 (1949)

18) Scott, D. W., J. P. McCullough, W. D. Good, J. F. Messerly, R. E. Pennington, T. C. Kincheloe, I. A. Hcssenlopp, D. R. Douslin and G. Wadoington: J. Am. Chem. Soc., 78, 5457 (1956)

19) Stockmayer, W. H. : J. Chem. Phys., 9, 398 (1941)

20) The Society of Chemical Engineers, Japan: Bussei Teisu, Vol. 1, Maruzen, Tokyo (1963)

21) Ibid,: Bussei Teisu, Vol. 2, Maruzen, Tokyo (1964)

22) Ibid. : Bussei Teisu, Vol. 3, Maruzen, Tokyo (1965)

23) Ibid,: Bussei Teisu, Vol. 4, Maruzen, Tokyo (1966)

24) Ibid,: Bussei Teisu, Vol. 5, Maruzen, Tckyo, (1967)

\title{
FORMULATION AND PREDICTION OF QUATERNARY VAPOR- LIQUID EQUILIBRIA ACCOMPANIED BY ESTERIFICATION*
}

ISAO SUZUKI, HIROMASA KOMATSU AND MITSUHO HIRATA Dept. of Ind. Chem., Faculty of Eng., Tokyo Metropolitan University, Tokyo

\begin{abstract}
Quaternary vapor-liquid equilibria with esterification have been formulated mathematically. First, activity coefficients have been related to liquid compositions with polynomial equations derived from the Margules model, and second, the parameters $B_{i}$ defined in an equation of the vapor-liquid equilibrium ratio with esterification reported previously have been represented by polynomials. Both correlations are adequate to describe the behavior of the given systems.

Vapor-liquid equilibrium with reaction of the system acetic acid-ethanol-water-ethyl acetate was predicted from Wilson's parameters obtained from binary system data only. Association equilibrium constants of dimerization and trimerization in acetic acid vapor were used to calculate modified activity coefficients, and WiIson's parameters were determined from six binary data. The agreement of the calculated and experimental data may be considered satisfactory for the practical use to design multicomponent distillation column reactors.
\end{abstract}

Although industrial esterification processes utilize fractionating columns as continuous reactors, the approach to their design and operation has been largely empirical. But many investigations have shown that the extent of conversion at each stage could be predicted from reaction-rate data, and that successive plate-to-plate design calculations could be made by utilizing experimental vapor-liquid equilibrium data and kinetic and equilibrium relations.

Previously, the authors reported on vapor-liquid equilibria of quaternary systems with esterification, such as acetic acid-methanol-water-methyl acetate ${ }^{8}$, acetic acidethanol-water-ethyl acetate ${ }^{\eta\rangle}$ and acetic acid-butanolwater-butyl acetate $^{62}$, and derived the relations with graphical correlation for the above systems.

In the present paper, we have tried to formulate relations between the liquid and vapor compositions or graphical correlations for solving the complex equations of multicomponent distillation column reactor design by

\footnotetext{
* Received on August 8, 1969
}

use of computer, and to estimate the above quaternary vapor-liquid equilibrium data from parameters obtained from binary system data only.

\section{Formulation of the Quate rnary Vapor-Liquid Equilibrium Data with Esterification}

This work was started with the Margules equation ${ }^{5>}$ modified by Marek which might be applicable to express the quaternary system vapor-liquid equilibrium data in esterification. The Margules constants were evaluated so as to minimize the sum of the squares of the difference between the observed and fitted values of the excess free energy suggested by Wohl, using experimental quaternary data, and the validity in vapor compositions was tested. But this system is far from ideality in liquid phase, so this trial failed to obtain good relations.

We then tried to rearrange the Margules equation as a polynominal series in mole fractions of the components in the mixture. The corresponding equation for its coefficient can be rearranged to the form 